the soft lens-matter was scooped out through a small corneal incision eighteen days after the injury. There was more perception of light after the first operation. Thirteen days afterwards, the greater part of the remaining lens-substance was scooped out. The patient immediately recognised people; and six days afterwards left the Hospital.

CASE vi. D. A., aged 19, suffered from detachment of the iris, followed by cataract. Linear extraction was performed. The patient sees at present to recognise people. The duration of treatment was seven days.

CASE VIr. T. S., aged 26 , had sequelæ of former inflammation of the globe of the right eye. The iris was dragged into a corneal cicatrix near the outer lower edge; the cornea was flattened and wrinkled; the globe was soft and squared; perception of light was present. On December $2 n d$, the broad needle, introduced at the outer corneal edge, was advanced between the cornea and iris to the middle portion of the latter; then thrust through it, and the wound enlarged on withdrawing the needle. On December 21st, with this eye, the patient saw the window well. 'The left eye was softish; the cornea flat; part of the pupil was occluded by a chalky deposit. The patient recognised features with this eye. On December 2 nd, a corneal incision, about four lines long, was made; and the deposit was detached with scoop and iris-forceps. Considerable force was used in doing this; and one-third of the fluid vitreous humour escaped. On December 21st, there was a central irregular pupil; no pain or inflammation. The patient sees large print. No active inflammatory symptoms were present before these operations.

Six cases of false membranes in the area of the pupil were treated with one or two needles. Among them was a case of congenital cataract, in which both lenses had several times been touched with the needle. On admission, the lenses gave the impression of flattened grey membranes, which Mr. Streatfeild opened out with two needles, when the vitreous humour advanced, dilating the pupil. On first sight, such a black pupil is very satisfactory; and, in several cases, the result was favourable, and was not disturbed by inflammatory symptoms. In other cases, this admission of vitreous humour into the pupillary area was followed by sickness and severe pain, and other inflammatory symptoms in the exe. This gives rise to the question, Are there any, and if so, what cases, in which the posterior capsule can be wounded with impunity?

vir. Excision of THE Globe. D. H., aged 13. Removal of the right globe was performed for general staphyloma, after purulent ophthalmia. Hardly any bleeding occurred. The patient left the Hospital three days after excision.

\section{OBtiatial Communitations.}

\section{ON THE MORTALITY OF INFANTS IN FOUND- \\ LING INSTITUTIONS, AND GENERALLY, AS INFLUENCED BY THE ABSENCE OF BREAST-MILK.}

By C. H. F. Tourth, M.D., Physician to the Samaritan Free Hospital for Women and Children; late Physician to the St. Pancras Royal Dispensary; etc.

[Read brfore the Nedical Soctety of London, October 17th, 1857.] Part I (concluded).

Passing on from these general causes of mortality, but which affect more severely foundlings, I proceed to speak of some of those to which children of this class are particularly exposed: and here, in the first place, I should premise that such children are by their very constitution particularly obnoxious to disease. Thus remarks M. De Watteville: "These unfortunate children in general have already been injured while yet in their mothers' wombs; a very large proportion suffering, from their birth, from defects of body which, later in life, quite unfit them for labour. And then, it should be added, want of care in infancy, whether in a hospital or when put out at nurse, contributes a great deal to make them weakly and obnoxious to disease."

1. Effect of Removal. Under this head we have conflicting opinions. From Mr. Wakefield's tables, it appears that 57 per cent. of all infants who had been brought from a distance of more than fifty miles died in the hospital, whereas the mortality among other children did not exceed 48 per cent.difference of 11 per cent. from this cause alone. M. Gaillard

brings out the same point by comparing the mortality of foundlings deposited in the town and hospice of Poitiers, as compared with that of infants who were merely removed there from the Maternite. During six warm months, seven of the former died to six of the latter; during six winter months, nineteen of the former died to ten of the latter. $\Lambda t$ Poitiers most came from a distance, whereas at Lyons they were mostly supplied by the city itself. 'This appears natural. A child brought a long way very soon after its birth, the mother probably too ill to accompany it, fed in the interim in a very im. proper manner, weakened by hunger and fatigue, is placed, no doubt, under very unnatural and unfavourable circumstances; yet it is a question how far, in practice, this rule applies. Wo learn from M. De Watteville's book (Statistique des Etallissemens et Services de Bienfaisance, p. 2:3), that this mortality annot be due to the transport, since in other cases, where the children are not very ill, and not exposed, the mortality is actually decreased. Thus-

$$
\begin{aligned}
& \text { Out of 88i!) childien, aged from } 1 \text { day to } 2 \text { years. } \\
& \text { " } 12110 \quad " \quad 2 \text { years to } 6 \text { " }
\end{aligned}
$$

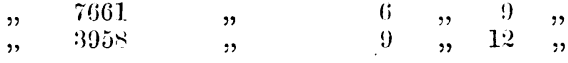

$$
\begin{aligned}
& 32605
\end{aligned}
$$

Exclusive of 8,000 who were taken out of these institutions by their parents, only 13 died during the journev, and 209 only in the month following their remoral $-\mathbf{a}$ cypher of mortality positively below that which obtains in such institutions. No doubt, want of care, and neglect of infants in removal, will in crease the mortality; and in this way we may perhaps explain the differences of opinion. This is best considered, however, under the next head.

2. Effect of Exposure. No doubt this is a great cause of mortality in foundling institutions. On comparing the French returns before given, the percentage mortality of exposec children, as compared to that of the ordinary foundlings, was as follows :-

\title{
Exposed Children.
}

In the Departments.

Where it was highest

Where it was lowest

Mean Foundlings.

Where it was highest

Where it was lowest

IIean

Highest. Lowest. (i:3.3 to 60. 19.2 to 0 $i 2.4$ to 13.4 50. to 20 . 5. to 0

- 215.5 to 3.0

(See this table in full, at page 46 .

Upon this point $\mathrm{Mr}$. Brownlow speals admirably in his very interesting work (Memoranda of the Foundling Hospital) of the great mortality in the building. He says: "This practice of transporting children from remote towns was condemned by a distinct resolution of the House of Commons, and a Bill was ordered to be brought in to prevent it; but this Bill was never presented; so that parish officers and others still continued to carry on their illicit trade, by delivering children to vagrants, who, for a small sum of money, undertook the task of conveying them to the hospital, although they were in no condition to take care of them, whereby numbers perished for want, or were otherwise destroyed; and, even in cases where children were left at the hospital, the barbarous wretches who had the con veyance of them, not content with the gratuity they received, stripped the poor infants of their clothing into the bargain, leaving them naked in the basket at the hospital." (p. 1 $1 ; 3$.) Indeed, Mr. Wrottesley, in his report to the House of Cornmons, states what is almost too horrible to believe-" that parents brought their children in a dying state, for the purpose of having them buried at the expense of the hospital." (Report of 1836.)

Mr. Brownlow makes, a little further on, the following very pertinent remarks: "It has been truly said, that the frail tenure by which an infant holds its life will not allow of a remitted attention even for a few hours. Who, therefore, will be surprised, after hearing under what circumstances most of these poor children were left at the hospital gates, that, instead of being a protection to the living, the institntion became as it were a charnel-house for the dead? It is a notorious fact, that 
many of the infants received at the gate did not live to be carried into the wards of the building; and, from the impossibility of procuring a sufficient number of proper nurses, the emaciated and diseased state in which many of these children were brought to the hospital, and the cruel conduct of some of those to whom they were committed (notwithstanding these nurses were under the superintendence of certain ladies, sisters of charity), the deaths amongst them were so frequent that out of the 14,934 received, only 4,400 lived to be apprenticed out, being a mortality of more than 70 per cent." (p.175.) These children were doubtless deprived of breast-milk. To attribute their death, however, to this cause, would be manifestly uniust.

3. Influence of Season. The mortality of children is usually believed to be greater in winter than at other seasons, because the weather is so much colder. The Abbe Gaillard pointed out this contingency in the case of the Foundling Institution at $\mathrm{X}$. Thus, in November and December 1829, out of 29 children, 19 died in the first month after admission; whereas, in July and August of the same year, there died only 11 out of 25 admitted. We all know, also, from the RegistrarGeneral's return, bow the mortality is increased by a cold $G$ week, the very young and old suffering urder its baneful influence. The conclusion, however, which I am bound to come to is, that, in public institutions, the great $\in \mathrm{r}$ number of deaths take place in spring, the least in autumn. It appears that, the deaths being 100 in all seasons, 30.8 will take place in spring; in summer and winter, it will be about the same- $27 \cdot 1$; while in autumn it will be least, only $14 \cdot 3$. The effect may be 0 somewhat varied out of public institutions; but in these, extending over a period of ten years, the results must be ad. mitted as true.

Mortality in Ireland from June 6th, 1841, to March 30th, 1851, in Public Institutioris.

\begin{tabular}{|c|c|c|c|c|c|c|c|c|c|c|c|c|c|}
\hline \multirow{2}{*}{\multicolumn{2}{|c|}{ Age. }} & & & & \multirow[b]{2}{*}{ Spring. } & \multirow[b]{2}{*}{ Summer. } & \multirow[b]{2}{*}{ Winter. } & \multirow[b]{2}{*}{ Autumn. } & \multirow{2}{*}{$\begin{array}{c}\text { All } \\
\text { Seasons. }\end{array}$} & \multicolumn{4}{|c|}{ PFR CENT. } \\
\hline & & & & & & & & & & Spring. & Summer. & Winter. & Autumn. \\
\hline One month and & nd & & & . & 15,106 & 13,128 & 13,506 & 7009 & 48,569 & 31. & $2 \pi .2$ & 27.7 & 14.4 \\
\hline Two months . & & & - & • & 3694 & 3443 & 3409 & 1806 & $12, \pm 52$ & 29.5 & 27.5 & 27.2 & 15.8 \\
\hline Three months & & & . & . & 4619 & 4810 & 4607 & 2636 & 16,672 & 27.6 & 28.2 & 27.5 & 16.7 \\
\hline Four months . & & . & . & . & 2163 & 2187 & 2199 & 1032 & 7781 & $2 \pi$ & $2 \pi .1$ & $2 \pi .1$ & 18.8 \\
\hline Five months . & 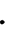 & & . & . & 1300 & 1174 & $13 \pm 9$ & 738 & 4501 & 28.4 & 25.4 & 29.1 & 17.1 \\
\hline Six months . & • & • & . & . & 5684 & 4895 & 4514 & 2692 & $18, \pi 85$ & 30.2 & 26. & 21. & 10.2 \\
\hline Seven months. & - & . & . & . & 1428 & 1252 & 1428 & 796 & 4801 & 29.7 & 26. & 29.7 & 14.6 \\
\hline Eight months . & . & - & . & . & 1388 & $12: 35$ & 1352 & 1078 & 4653 & 29.5 & 26.2 & 28.7 & 15.6 \\
\hline Nine months . & . & . & . & . . & 4815 & 4088 & 4219 & 2067 & 15,189 & 31.6 & 26.8 & 27.7 & 13.9 \\
\hline Ten months . & • & . & . & . & 1654 & $13 \pm 2$ & 1426 & 677 & 5099 & 82.4 & 26.3 & 27.9 & 13.3 \\
\hline Fleven months & 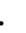 & . & . & . & 1346 & 1103 & 1075 & 614 & 4238 & 32. & 26.2 & 25.6 & 16.2 \\
\hline One year . . & . & • & . & . & $25, \pi 16$ & 22,484 & 21,841 & 10,886 & 80,926 & 81.9 & $2 \pi .8$ & 26.9 & 13.4 \\
\hline Two years. & & . & . & . & 22,759 & 18,639 & 18,113 & $87 \pm 8$ & 67,259 & $33 . \tau$ & 27.6 & 26.9 & 11.8 \\
\hline Three years & . & . & . & . & 15,837 & 13,500 . & 12,558 & $607 \pm$ & $4 \pi, 969$ & 32.9 & 28.1 & 26.1 & 12.9 \\
\hline Four years. . & & $\cdot$ & . & . & 13,381 & 11,327 & 10,140 & 5048 & 39,926 & $3: 5$ & 28.1 & $2 \pi .9$ & 10.5 \\
\hline Five to ten years & . & . & . & . . & 44,161 & 36,954 & 29,6617 & 15,823 & 126,605 & 34.7 & 29. & 23.4 & 13.9 \\
\hline Mean & & - & • & - & & & & & & 30.8 & $2 \pi .1$ & 27. & 14.3 \\
\hline
\end{tabular}

4. Influence of the Recumbent Position and Want of Exercise. In the Cinion MIédicalc, November 2nd and $23 \mathrm{rd}, 1852$, are two very able papers by M. Hervieux, on the abuse of the horizontal position at the Hospice des Enfans Trouvés, and its influence on the mortality of the newly born infants. The following is an abstract.

The nursery of this hospital is sixty feet long by twenty wide, and from twenty to twenty-five feet high. Light is introduced by ejght windows, besides a painted one. The tempera. ture is kept up by a large fireplace in the centre, around which persons can sit at ease, besides two large stoves at each extremity; so that the heat is equally diffused. Dry oak boards, coverel by carpets, constitute the flooring; and the walls always appear most dry.

The linen is very clean and white; altogether, everything that could be desired, in the way of neatness and cleanliness, is carried into effect.

In this room are eighty-four cots to receive infants. Nine women are engaged in feeding and cleaning these little creatures, which is done four times a day, 6 A.x., 9 A.sr., 12, and 1 r.m. The food is given in the spoon. Besides these nine day nurses, there are two night nurses employed in the same way all night. Thus, including the most restless and the quietest children together, it may be assumed, on an average, that each child is taken up six times a day. To clean and feed a child would occupy about twenty-five minutes in the hands of inexperienced nurses, ten or fifteen in the hands of those more experienced. Thus, the children, on an average, are held twenty minutes- $6 \times 20=120$; so that each child has only two out of twenty-four hours exercise or movement. Now, what is the effect of this? A child, under natural circumstances, even if fed, generally lies upon the bosom of its mother or nurse; here he obtains artificial heat; and, in the hands of others, through the shaking, petting, etc., he obtains ample exercise. Thus his heat is maintained. But, short of this exercise, the temperature of the child's body will fall, the extremities will cool; the circulation become slower; the respiration will be embarrassed; all the major functions will fail; the cellular tissue will harden; the visceral organs will become congested; some will die by "sclerema", others by passive pneumonia (which is, after all, only proof of congestion of the lungs), some of serous effusion or hæmorrhage in head or spinal cord. These are simply the results of cold superadded to those of starvation.

Now, in order to prove that these children are starved, M. Hervieux proceeds to speak against the system of feeding infants only at regular hours. Looking at the case of many infants who keep sucking thirty to forty times a day, very often kept constantly to the breast, MM. Natalis Guilliot and Lamperière, of Versailles, have shown that infants absorb in the twenty-four hours from 48.1 to $60.4 \mathrm{oz}$. Such children thrive wonderfully; and hence to stint and feed a $\delta$ child so precisely by rule-a child who, in the earlier two or three years of life, gains half the height and weight he will acquire in all his life, is little less than absurd.

'Th1s large amount of food has been objected to, as giving rise to gastritic derangement; but if no such diseases should of be found in towns, among the rich and those poor who, when $D$ they can do so, aimost always overfeed their children, this objection cannot be correct. It is true, part of the mortality of such infants may be attributed to the hereditary taint from diseased $N$ parents, to the close aggregation of the infants in the hospital, $\underset{\omega}{\mathbf{W}}$ and often to the injurious artificial food which has been $\sigma$ supplied. But there must be something more than this; many poor diseased parents inhabiting filthy localities, and $\varrho$ even often in want (although, to their credit be it said, the milk will often be provided for the child, though the parents want the common necessaries), have children who thrive. A child wants good food and air; but this will not suffice; he requires to be moved about; should go out in the open air and sun; and should be properly attended, in a hygienic as well as a dietetic manner. M. Hervieux therefore recommends that, instead of nine, there should be at least thirty-six nurses to tend the children.

5. W'ant of Breast-Milk. It is to the deprivation of this kind of food that the mortality is usually assigned. Now, I believe 0 this is only one of several causes-a powerful one, no doubt, but still, I believe, in its effects much exaggerated. This becomes manifest if we look to the actual number of deaths attributable to want of breast-milk, as occurring in a general 
population, and irrespective of foundling institutions altogether. I have selected the Registrar-General's tables for London. In the quarterly returns, however, under this head, we are referred to cold, atrophy, and privation, as, no doubt, under these heads many cases are included which, properly speaking, should be returned under the head of death from want of breast-milk. Perhaps we should include some others, as, for instance, diarrhœa; albeit I make no doubt, though diarrhoea may have been present in most of these cases, as a symptom, death has been referred to the cause want of breast. milk. This is, however, only a supposition; and hence, in the impossibility to measure the amount due to diarrhœe, I am obliged to neglect it. I have, however, to make amends, included all cases of premature death and debility under one year old, which is a large number, and which must needs in. clude many who are not thriving under the poor breast-milk given, or the food substituted. Taking the six vears, 1819 to 1854 inclusive, I have the following table :-

Mortality of Infants from various causes.

\begin{tabular}{|c|c|c|c|c|c|c|c|}
\hline & 1849. & 1850. & 1851. & 1852. & 1853. & 1854. & Total. \\
\hline $\left.\begin{array}{r}\text { From all causes } \\
\text { under one year } \\
\text { old............ }\end{array}\right\}$ & 12208 & 10349 & 11631 & 12272 & 12981 & 13896 & 73227 \\
\hline & 5 & 2 & - & 2 & 1 & 1 & 11 \\
\hline & 3 & 1 & 3 & 3 & 4 & 2 & 16 \\
\hline $\begin{array}{c}\text { breast- } \\
\ldots \ldots \ldots\end{array}$ & $17 t$ & 178 & 229 & 240 & 255 & $33 \pi$ & 1413 \\
\hline & 8 & 4 & & - & 9 & 3 & 24 \\
\hline $\begin{array}{c}\text { Premature birth } \\
\text { and debility } \\
\text { under one year } \\
\text { old ......... }\end{array}$ & 1232 & 1241 & 1470 & 1537 & 1475 & 1518 & 8473 \\
\hline Atrophy, ditto . & $8 \pi 4$ & $75 \pi$ & 784 & 827 & 971 & 1091 & 5304 \\
\hline Total $\ldots . . .$. & 2296 & $218: 3$ & 2481 & 2609 & 2715 & 2952 & 15241 \\
\hline All births & 72612 & & & & & 81885 & \\
\hline
\end{tabular}

Therefore, out of 473,865 births in six years, 15,241 , or $3 \cdot 2$ per cent., died from want of breast-milk in its widest sense; or, out of 73,227 deaths from all causes, occurring to children under one year old, 20.8 per cent. might be referred to deprivation of this kind of diet.

My own experience completely bears out these conclusions. I am connected with two institutions which, each in their way, have satisfied me that the congregation of foundlings or children whom we sought to bring up by hand in this town was almost invariably fatal; so that their distribution, even in circumstances of poverty, was almost always less injurious, often their salvation.

An attempt was made in connexion with one of these-an infant nursery, where children are received during the day, in the absence of their working parents, cared for, and fed-to take in boarders, that is to say, the infants of mothers who were engaged as wet nurses. A large nursery, well aired, scrupulously clean, temperature uniform, $70^{\circ}$ usually, in which an experienced nurse, directing four or five young women in the arrangement of the children, was placed,- was selected. The most approved system of diet was enforced; and yet none of these children throve. The mortality was certainly 4 out of 5 , if not more. The diseases that prevailed were-diarrhœa, which resisted all treatment, the pcst mortem appearances in such cases being usually null, or consisting of a simple thickening of Peyer's glands, similar to what we see among some cases of Asiatic cholera; aphthæ or diphtherite, with or without diarrhœa In these cases, solution of nitrate of silver, in mirute doses, or as a lotion to the mouth, was the only remedy which seemed ever to do good. This disease was fearfully contagious, and no measures of precaution could prevent its extension : indeed, to such a degree was it so, that, on one occasion, two of the big girls in attendance were seized with a kind of ulceration in the conjunctiva, having much the appearance of scrofulous ophthalmia, only the ulcers were more lengthened, and there was no photophobia. These cases did not recover till after the application of nitrate of silver in substance. Chloride of lime was largely used in the rooms; the whole walls were washed with a solution of it. The same spoon was never used to another child, and always washed after use in a solution of chloride of lime.
A separate nipple was kept for each child. Still the disease often recurred, and proved equally contagious. Lastly, atrophy prevailed largely; it often succeeded the cases of diphtheritis which recovered. Sometimes, however, it was the only symp. tom present. These children ate enormously, but got thinner and thinner, till at last they died, with all the symptoms of inanition. Usually, a removal from the institution led to a recovery; except, however, in those cases of atropiny. 'This disease, once induced, generally persisted, and proved fatal.

The other institution was a penitentiary for females of a better class, but who, having fallen once, were taken in to be confined and recluimed. Many of these went out as wet nurses. Some of the infants came to the nursery before spoken of; others were brought up by the hand, by friends of the patients. $\Lambda$ mong the latter I did not trace one case of death. Although this statement should be talsen with reservation, as, after some months, the children were lost sight of, still there is no doubt that, although these infants were brought up in circumstances of poverty, and that those who cared for them were often in penury and want, yet they throve better and proved longer lived than our nursery infants. I have no doubt that the causes enumerated by iI. Hervieux, the hospital atmosphere, the insufficiency of external exercise, contributed greatly to these results. I might perhaps add another-the inaptitude of the assistants to the head nurse, and their inexperience of children. I am sure $I$ have seen this in private practice. I have seen a child under the care of a nurse, and that nurse exact, too, in her duties, but not a mother, or having had much experience in the handling of children; that child has pined away, and become weak and thin. An experienced mother has now taken the child in hand; and, albeit the same food has been given, and apparently, in as far as regards external circumstances, the child has been placed exactly as before, it has now thriven well, and recovered health and strength speedily. I cannot measure the extent of this influence by figures, but of its existence and powerful operation I have no doubt.

These are a few of the reflections which I have ventured to commit to paper, which, I hope, may prove of interest to the Society, and calculated to elicit discussion. I had hoped to have entered upon the subject of the effect of diet on the mortality of children, and foundlings in particular. The length, however, to which this paper has already extended, precludes this. On a future occasion, if the Society will allow me, I shall return to the subject. I think, however, enough has been said to show that, however injurious the want of breast-milk may be, it is somewhat exaggerated, more especially taking in connexion the fact observed by $\mathrm{M}$. Benoiston de Chateauneuf, that the mere substitution of a bired wet nurse for a mother increases, as before seen, the mortality $10^{\circ} 6 \pm$ per cent.

To recapitulate, therefore, I have shown-

1. That, for the ages one year and under five, the mortality, even under ordinary circumstances, is in towns nearly double what it is in country; but this difference in the mortality according to residence is nearly seven times as great for foundlings: therefore, foundlings should never he main. tained in towns.

2. Thet in Ireland, while it is doubtless very high in the first month, for those under one year it is only 30 per cent. in towns, to 22 per cent. in country; the worst mortality with foundlings being 50 per cent.

3. That travelling in fair seasons is not dangerous to foundlings.

4. That the mortality is greatest in spring, and least in autumn, with children in public institutions.

5 . That a chief cause in the mortality of foundlings is want of exercise, and the abuse of the recumbent position.

6 . That want of breast-milk will only account for a mertality of 3.4 per cent. additional.

7. That a depraved hospital atmosphere and certain en demic contagious disorders are the chief cause of the mortality in foundling hospitals; from which results we are justified in concluding- $(a)$ That if foundling hospitals are to be maintained at all, they should be always built in the country. (b) That large open single wards should be converted into small well ventilated rooms, capable of containing from three to four cots, with one nurse at least to each small ward so constructed. (c) That, where it can be done, wet nurses should be supplied, and preference, if possible, should be given to the children's mothers. (d) That means should be taken to ensire the proper exercise of the infants.

52, Montagu Square, London, November $185 \%$. 


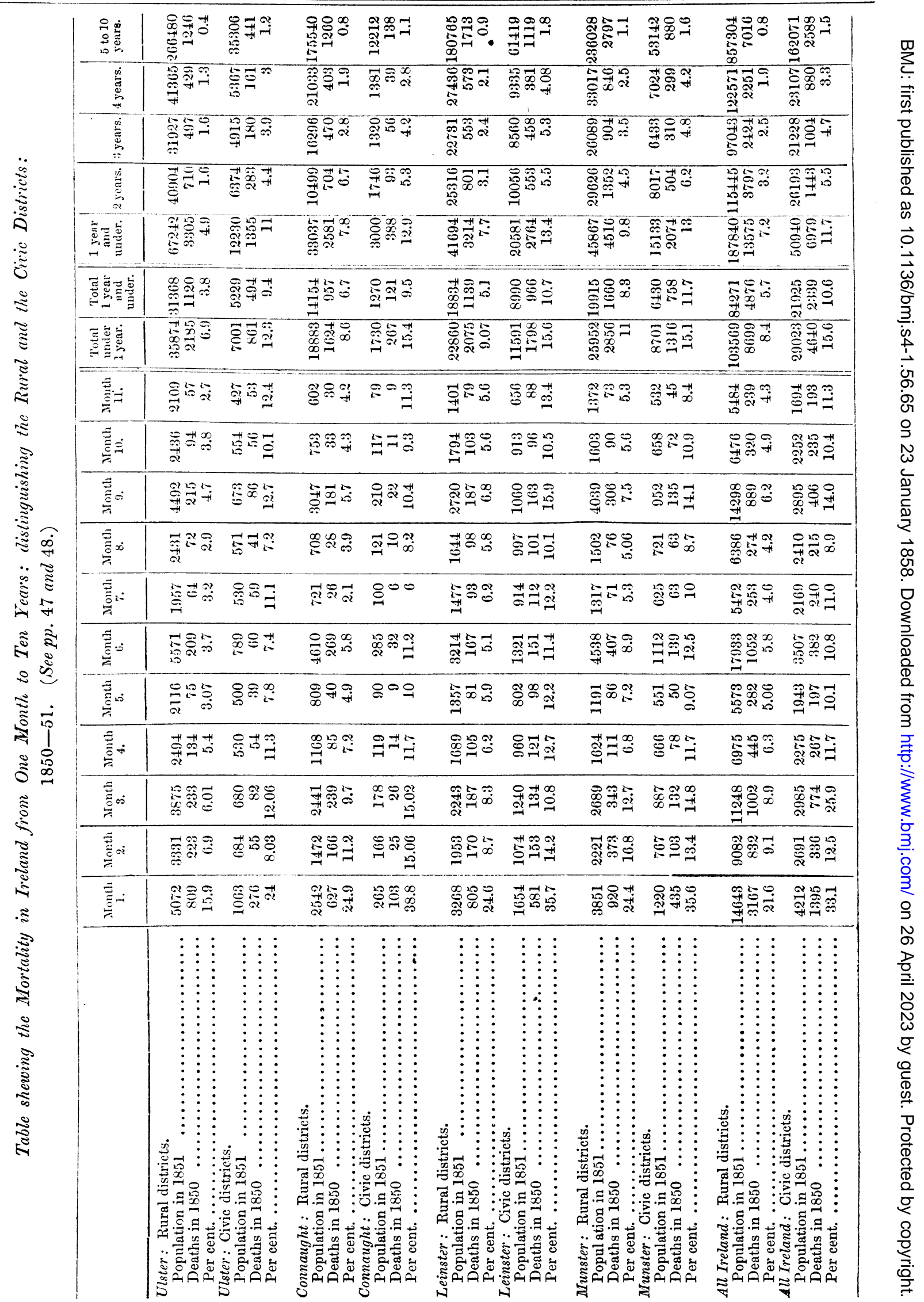

